This is the postprint version of the following article: Gurruchaga-Pereda, J; Martinez-Martinez, V; Rezabal, E; Lopez, X; Garino, C; Mancin, F; Cortajarena, AL; Salassa, L. Flavin Bioorthogonal Photocatalysis Towards Platinum Substrates. ACS Catalysis 2019, DOI: $\underline{10.1021 / a c s c a t a l .9 b 02863}$

This article may be used for non-commercial purposes in accordance with ACS Terms and Conditions for Self-Archiving. 


\title{
Flavin Bioorthogonal Photocatalysis Towards Platinum Substrates
}

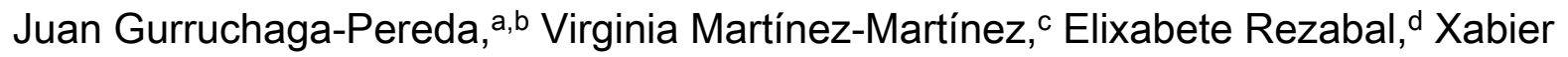 \\ Lopez, ${ }^{\mathrm{a}, \mathrm{d}}$ Claudio Garino, ${ }^{\mathrm{e}}$ Fabrizio Mancin, ${ }^{\mathrm{f}}$ Aitziber L. Cortajarena, ${ }^{\mathrm{b}, \mathrm{g}}$ Luca Salassa ${ }^{\mathrm{a}, \mathrm{g}^{*}}$
}

a Donostia International Physics Center, Paseo Manuel de Lardizabal 4, Donostia, 20018, Spain

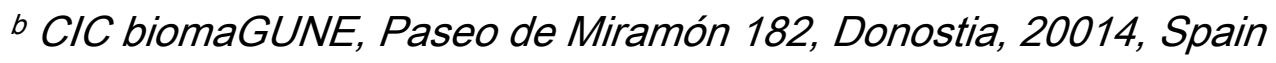

c Departamento de Química Física, Universidad del País Vasco, UPVIEHU, Apartado 644, Bilbao, 48080, Spain

${ }^{a}$ Kimika Fakultatea, Euskal Herriko Unibertsitatea, UPVIEHU, Donostia, 20080, Spain

e Department of Chemistry, University of Turin, via Pietro Giuria 7, Turin, 10125, Italy

${ }^{f}$ Dipartimento di Scienze Chimiche, Università di Padova, via Marzolo 1, Padova, 35131, Italy

g Ikerbasque, Basque Foundation for Science, Bilbao, 48011, Spain

\begin{abstract}
Catalytic reactions that use metal complexes as substrates, rather than catalysts, are nearly unknown. We recently demonstrated that certain flavins (FLs) are potent redox photocatalysts capable of converting $\mathrm{Pt}^{\mathrm{IV}}$ anticancer prodrug complexes into $\mathrm{Pt}^{\mathrm{II}}$ drugs in the biological environment. Herein, we investigate the mechanism of these artificial photocatalytic reactions employing four different free flavins, namely riboflavin (Rf), flavin mononucleotide (FMN), tetra-O-acetyl riboflavin (TARF) and lumiflavin (Lf), and the flavoprotein miniSOG (mini Singlet Oxygen Generator) together with a panel of $\mathrm{Pt}^{\mathrm{IV}}$ substrates conveniently selected.

NMR, steady-state and time-resolved optical spectroscopy studies highlight that light activation of FLs in the presence of NADH as electron donor ( $\mathrm{pH} 7-7.5$ ) eventually leads to the generation of the reduced $\mathrm{FLH}^{-}$species which catalyzes the $\mathrm{Pt}^{\mathrm{IV}}$-to- $\mathrm{Pt}$ "l conversion with turnover frequency (TOF) values ranging between 1.3 and $30 \mathrm{~min}^{-1}$, and turnover number (TON) values reaching 500. Comparable catalytic efficiency is also found for reactions performed in cell culture medium. Density functional theory suggests that activation via reduction of the $\mathrm{Pt}^{\mathrm{IV}}$ complexes may be influenced by $\mathrm{H}$-bonding interactions between the FL catalyst and the metal substrate and confirm that both the isoalloxazine
\end{abstract}


and ribityl moieties of the FLs determine the catalytic efficiency of the process. The FMNcontaining miniSOG is a less effective catalyst (TOFs $<5.6 \mathrm{~min}^{-1}$ ) since the formation of the doubly reduced $\mathrm{FMNH}^{-}$competes with an electron transfer reaction involving the protein matrix which quenches the FMN excited state to give a singly-reduced FMN*-.

\section{KEYWORDS}

Photocatalysis, Flavins, Bioorthogonal catalysis, Platinum prodrugs, Chemotherapy, Photoactivation

\section{INTRODUCTION}

In catalysis, coordination and organometallic complexes typically act as catalysts to kinetically favor the conversion of organic substrates into added-value products. Recently, we subverted such a paradigm to conceive new approaches for the activation of metalbased anticancer prodrugs (Figure 1). ${ }^{1-4}$ We demonstrated that flavins (FLs) can perform under light-irradiation as catalysts to prompt the transformation of transition metal substrates into their biologically active counterparts. In the presence of electron donors, flavin co-factors and certain flavoproteins are able to photoconvert $\mathrm{Pt}{ }^{\mathrm{IV}}$ precursors into cisplatin or carboplatin within biological environments, switching on the antiproliferative activity of the $\mathrm{Pt}$ ll drugs in vitro. This unconventional approach expands the substrate scope and versatility of bioorthogonal catalytic reactions currently available in drug development, ${ }^{1,5,6}$ potentially creating new uses for a myriad of inorganic biological agents that have been developed over the last decades as chemotherapeutics and antibacterial agents. The term bioorthogonal here refers to the capacity of these catalysts to attain multiple substrate turnovers and high selectivity towards the $\mathrm{Pt}^{\mathrm{IV}}$-to- $\mathrm{Pt}$ "l conversion in a complex biological environment.
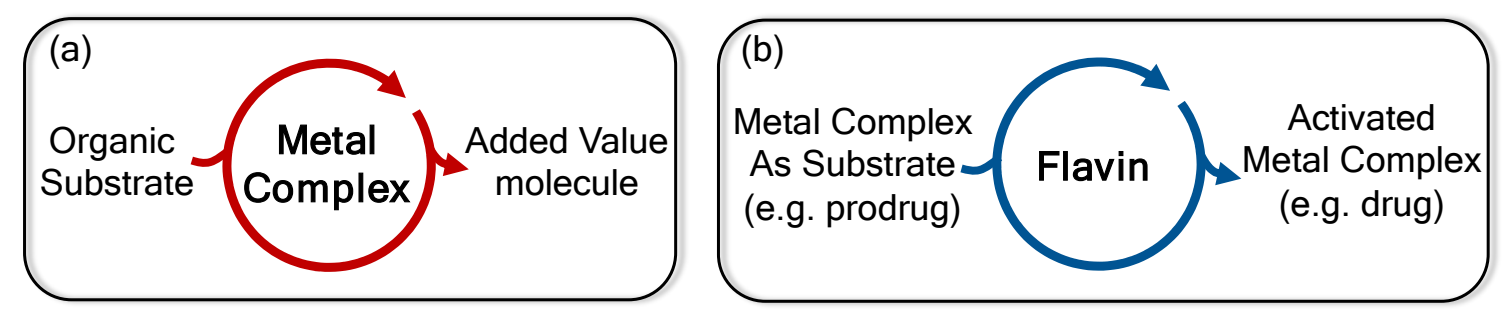

Figure 1. (a) Metal-based catalysis and (b) catalysis towards metal substrates.

Our proof-of-concept studies on flavins, Megger's enantioselective synthesis of $\left[\mathrm{Ru}(\mathrm{bpy})_{3}\right]^{2+}$ via organocatalysis ${ }^{7}$ and the recent aromatic amination of cyclometallated $\mathrm{Ru}^{\text {Il }}$ and $\mathrm{Rh}$ "II octahedral complexes reported by Leonori ${ }^{8}$ are, to the best of our knowledge, 
unique examples of catalytic reactions that use metal complexes as substrates. This uncharted territory may offer intriguing opportunities to expand synthetic inorganic chemistry and foster new catalysis-based applications for coordination and organometallic compounds.

In view of such a perspective, this study aims at expanding the boundaries of catalysis towards metal substrates by providing a detailed understanding of the mechanism through which flavins (photo)catalyze the activation of $\mathrm{Pt}^{\mathrm{I} \vee}$ complexes. Herein, we gather novel insights into the catalytic mechanism and rationalize how changes in the structure of flavin catalysts and $\mathrm{Pt}^{\mathrm{IV}}$ substrates significantly affect reaction outcomes.

This work also reports fundamental information on the redox chemistry of flavins towards transition metals. For instance, flavoenzymes such as mercuric reductase regulates $\mathrm{Hg}$ resistance in several organisms by promoting the conversion of highly toxic $\mathrm{Hg}^{\text {"l species }}$ to less dangerous $\mathrm{Hg}^{0} .{ }^{9}$ Hence, findings described in this manuscript may have potential implications in the biochemistry and in the cell homeostasis of metals.

\section{RESULTS AND DISCUSSION Catalysis studies}

We employed five flavins and four Pt'v prodrug complexes to investigate the catalyst and substrate scope for the reduction of anticancer metal complexes (Figure 2). We selected riboflavin (Rf), riboflavin-5'-phosphate (FMN), 2',3',4',5'-tetraacetylriboflavin (TARF) and lumiflavin (Lf) to assess the role of the ribityl side chain in the catalytic transformation of metal substrates. As shown in Figure S1 and in previous studies, ${ }^{10}$ the photostability of flavin derivatives strongly depends on this fragment (TARF $\sim$ Lf $>$ Rf $\sim$ FMN). The flavoprotein miniSOG (mini Singlet Oxygen Generator) ${ }^{11}$ was included in our panel of catalysts to gauge the impact of an amino acid scaffold around the flavin catalytic core on the catalysis. MiniSOG is a small FMN-containing fluorescent protein developed as CLEM (correlative light and electron microscopy) $\operatorname{tag}^{11}$ and investigated as photosensitizing agent, ${ }^{12,13}$ including for photodynamic therapy. ${ }^{14,15}$ We opted for cis,cis,trans$\left[\mathrm{Pt}\left(\mathrm{NH}_{3}\right)_{2}\left(\mathrm{Cl}_{2}\right)\left(\mathrm{O}_{2} \mathrm{CCH}_{2} \mathrm{CH}_{2} \mathrm{CO}_{2}\right)_{2}\right]^{2-}$ cis, cis, trans$\left[\mathrm{Pt}\left(\mathrm{NH}_{3}\right)_{2}\left(\mathrm{O}_{4} \mathrm{C}_{6} \mathrm{H}_{6}\right)\left(\mathrm{O}_{2} \mathrm{CCH}_{2} \mathrm{CH}_{2} \mathrm{CO}_{2}\right)_{2}\right]^{2-}$ (2), cis, cis, trans- $\left[\mathrm{Pt}\left(\mathrm{NH}_{3}\right)_{2}\left(\mathrm{Cl}_{2}\right)\left(\mathrm{O}_{2} \mathrm{CCH}_{3}\right)_{2}\right]$ (3), cis, cis, trans- $\left[\mathrm{Pt}\left(\mathrm{NH}_{3}\right)_{2}\left(\mathrm{O}_{4} \mathrm{C}_{6} \mathrm{H}_{6}\right)\left(\mathrm{O}_{2} \mathrm{CCH}_{3}\right)_{2}\right]$ (4) as $\mathrm{Pt} I \mathrm{~V}$ substrates because they are structurally similar, and yet present features that could influence the catalytic process. We envisaged that differences in the equatorial (chlorido versus cyclobutane dicarboxylato) and axial (succinato versus acetato) ligands of the complexes could affect the catalysis. 
Moreover, these complexes are of relevance in medicinal inorganic chemistry since they are either prodrugs of cisplatin (1 and $\mathbf{3}$ ) or carboplatin (2 and $\mathbf{4})$, two anticancer drugs clinically-approved worldwide. ${ }^{16,17}$

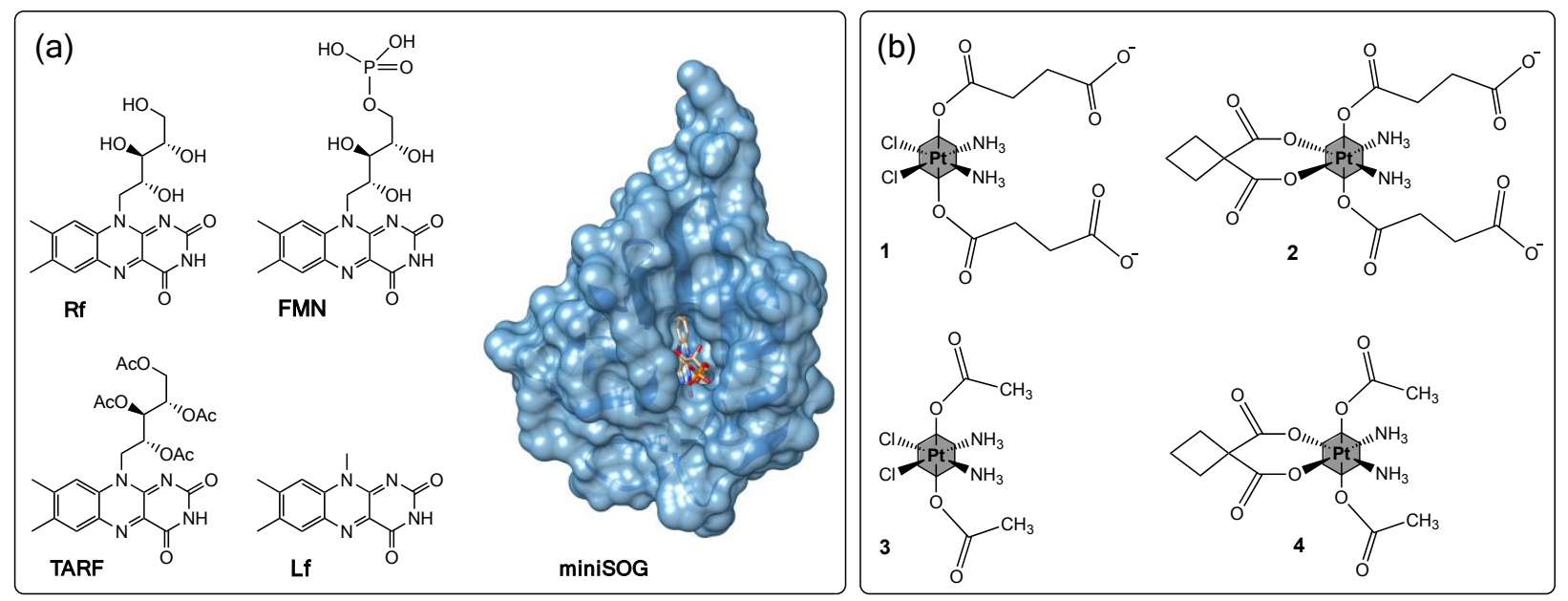

Figure 2. Structures of (a) catalysts and (b) substrates employed in this work. Catalysts: riboflavin (Rf), riboflavin-5'-phosphate (FMN), 2',3',4',5'-tetraacetylriboflavin (TARF), lumiflavin (Lf), mini Singlet Oxygen Generator (miniSOG). Substrates: cis, cis, trans- $\left[\mathrm{Pt}\left(\mathrm{NH}_{3}\right)_{2}\left(\mathrm{Cl}_{2}\right)\left(\mathrm{O}_{2} \mathrm{CCH}_{2} \mathrm{CH}_{2} \mathrm{CO}_{2}\right)_{2}\right]^{2-} \quad$ (1), cis, cis, trans$\left[\mathrm{Pt}\left(\mathrm{NH}_{3}\right)_{2}\left(\mathrm{O}_{4} \mathrm{C}_{6} \mathrm{H}_{6}\right)\left(\mathrm{O}_{2} \mathrm{CCH}_{2} \mathrm{CH}_{2} \mathrm{CO}_{2}\right)_{2}\right]^{2-} \quad$ (2), cis, cis, trans- $\left[\mathrm{Pt}\left(\mathrm{NH}_{3}\right)_{2}\left(\mathrm{Cl}_{2}\right)\left(\mathrm{O}_{2} \mathrm{CCH}_{3}\right)_{2}\right] \quad$ (3), cis, cis, trans$\left[\mathrm{Pt}\left(\mathrm{NH}_{3}\right)_{2}\left(\mathrm{O}_{4} \mathrm{C}_{6} \mathrm{H}_{6}\right)\left(\mathrm{O}_{2} \mathrm{CCH}_{3}\right)_{2}\right](4)$.

Unless otherwise stated, all photocatalysis experiments were performed in phosphate buffer (PB, $18 \mathrm{mM} \mathrm{pH} \mathrm{7)} \mathrm{using} 25 \mu \mathrm{M}$ catalyst (5\% loading), $500 \mu \mathrm{M}$ substrate (1-4) and $1 \mathrm{mM} \mathrm{NADH}$ (nicotinamide adenine dinucleotide) as electron donor. The choice of NADH was motivated by its participation in numerous biochemical redox reactions carried out by flavoproteins. ${ }^{18}$ Nevertheless, biological electron donors such as ascorbate can also be employed, whereas glutathione (GSH) is not efficacious in these reactions (Figure S2 and S3). Samples were irradiated with a $460-\mathrm{nm}$ LED light source $\left(6 \mathrm{~mW} \cdot \mathrm{cm}^{-2}\right)$ in the presence of $\mathrm{O}_{2}$. We evaluated reaction progression by ${ }^{1} \mathrm{H}$ NMR, monitoring the appearance and disappearance of diagnostic peaks corresponding to the coordinated and free succinato or acetato ligands of $\mathbf{1 - 4}$. The release of such ligands corresponds to the formation of biologically active $\mathrm{Pt}$ " species. ${ }^{2}$

The stability of complexes 1-4 (500 $\mu \mathrm{M})$ was initially tested in PB (18 mM) with NADH (1 $\mathrm{mM}$ ) over $48 \mathrm{~h}$ in the dark. We observed no decomposition of the $\mathrm{Pt}^{\mathrm{IV}}$ substrates in the absence of FLs (Figure S4). When flavins (25 $\mu \mathrm{M})$ were added to the PB buffered solution, conversion of 1-4 slowly occurred reaching 40 to $100 \%$ after $16 \mathrm{~h}$, except in the case of samples containing miniSOG that showed barely any change after $48 \mathrm{~h}$ (Figure S5-S9). Experiments performed using $\mathbf{R f}$ and $\mathbf{1}$ (Figure S10) revealed that the dark conversion of 
the substrate was faster at higher concentrations of $\mathbf{R f}(50-150 \mu \mathrm{M})$ and NADH $(2.5$ and $5 \mathrm{mM})$.

Dark reactivity of the different catalysts towards the substrates did not follow any specific trend. Complexes 2 and 4 partially afforded (5-40\%) free cyclobutane dicarboxylato (CBDA) ligand as reaction product in the presence of FMN, TARF and Lf. In addition, the photostability of metal substrates 1-4 was tested in the presence of $1 \mathrm{mM}$ NADH (18 mM $\mathrm{PB}, \mathrm{pH} 7$ ) under 460-nm light irradiation. Complexes 1 and 3 underwent approximately $20 \%$ conversion over $3 \mathrm{~h}$, while carboplatin derivatives did not show any light-induced reactivity (Figure S11). Under light irradiation, solutions containing 1-4 and catalytic amounts of $\mathbf{R f}$ did not present any significant substrate conversion in the absence of NADH (Figure S12), confirming the need for an electron donor for the catalysis to occur.

Table 1 and Figure 3 summarize catalysis results obtained for the different flavin catalysts and metal substrates under the conditions described above (see also, Figure S13-17).

Table 1. Turnover frequencies (TOFs, $\mathrm{min}^{-1}$ ), turnover numbers (TONs) and conversion (Conv.) percentages for the flavin-catalyzed photoactivation of 1-4 in the presence of NADH.

\begin{tabular}{|c|c|c|c|}
\hline Complex & TOF $\left(\min ^{-1}\right)$ & TON & Conv. [\%] \\
\hline \multicolumn{4}{|c|}{ Rf } \\
\hline 1 & $17.3 \pm 0.6$ & 20 & 100 \\
\hline 2 & $8.1 \pm 0.4$ & 20 & 100 \\
\hline 3 & $20.3 \pm 2.0$ & 20 & 100 \\
\hline 4 & $10.0 \pm 0.3$ & 20 & 100 \\
\hline \multicolumn{4}{|c|}{ FMN } \\
\hline 1 & $19.3 \pm 1.7$ & 20 & 100 \\
\hline 2 & $13.4 \pm 0.9$ & $17.9 \pm 0.2$ & $89.9 \pm 0.9$ \\
\hline 3 & $23.2 \pm 1.7$ & 20 & 100 \\
\hline 4 & $15.5 \pm 1.4$ & 20 & 100 \\
\hline \multicolumn{4}{|c|}{ TARF } \\
\hline 1 & $24.1 \pm 5.1$ & 20 & 100 \\
\hline 2 & $13.7 \pm 0.2$ & $18.5 \pm 0.2$ & $92.4 \pm 1.0$ \\
\hline 3 & $26.0 \pm 1.1$ & 20 & 100 \\
\hline 4 & $22.7 \pm 5.6$ & 20 & 100 \\
\hline \multicolumn{4}{|c|}{ Lf } \\
\hline 1 & $9.2 \pm 0.1$ & 20 & 100 \\
\hline 2 & $2.6 \pm 1.6$ & 20 & 100 \\
\hline 3 & $13.3 \pm 0.5$ & 20 & 100 \\
\hline 4 & $7.9 \pm 1.0$ & 20 & 100 \\
\hline \multicolumn{4}{|c|}{ minisOG } \\
\hline
\end{tabular}




\begin{tabular}{cccc}
\hline $\mathbf{1}$ & $3.7 \pm 0.2$ & 20 & 100 \\
$\mathbf{2}$ & $1.3 \pm 0.3$ & $14.7 \pm 0.7$ & $73.4 \pm 3.8$ \\
$\mathbf{3}$ & $5.6 \pm 0.3$ & $18.7 \pm 1$ & $93.7 \pm 5.5$ \\
& & & \\
$\mathbf{4}$ & $2.6 \pm 0.4$ & $17.5 \pm 0.6$ & $87.7 \pm 3.1$ \\
\hline
\end{tabular}

Photocatalytic reactions reached full conversion of 1-4 and turnover numbers (TONs) of 20 upon few minutes of light irradiation, the only exception being 2 with FMN and TARF and 2-4 with miniSOG. TOF values for free FMN were 4-6 times higher compared to FMNembedded in minisOG, and in the case of 2 even up to 10-fold higher. Notably, TONs reached significantly higher values when lower catalyst loading $(0.2 \%, 1 \mu \mathrm{M})$ and longer irradiation periods were employed. In the case of Rf, we observed TONs of 500 for $\mathbf{1}$ and $\mathbf{3}$ and of 423 and 468 for $\mathbf{2}$ and $\mathbf{4}$ respectively, upon approximately $2 \mathrm{~h}$ of light irradiation (Figure S18).

In general, cisplatin prodrugs $\mathbf{1}$ and $\mathbf{3}$ were more efficiently converted compared to their carboplatin analogues $\mathbf{2}$ and $\mathbf{4}$, affording superior turnover frequency values (TOF, $\mathrm{min}^{-1}$ ). The preference for cisplatin prodrugs was confirmed in substrate competitive experiments in which the conversion of couples of substrates was simultaneously tested (Figure S19 and S20).

Complex $\mathbf{3}$ showed the highest TOF for all flavin catalysts. The catalytic activity of Lf resulted in significantly lower TOFs compared to other flavins, reasonably suggesting that the ribityl chain plays an important role in the catalytic process (vide infra). Overall, 
miniSOG resulted the least efficient catalyst, with TOF values ranging 1.3-5.6 $\mathrm{min}^{-1}$, and showed similar reactivity as Lf towards substrate 2 . On average, the protein scaffold of miniSOG lowered reaction rates 6.4 times compared to free FMN which can be explained by the reduced substrate accessibility to the FMN when embedded in the protein.

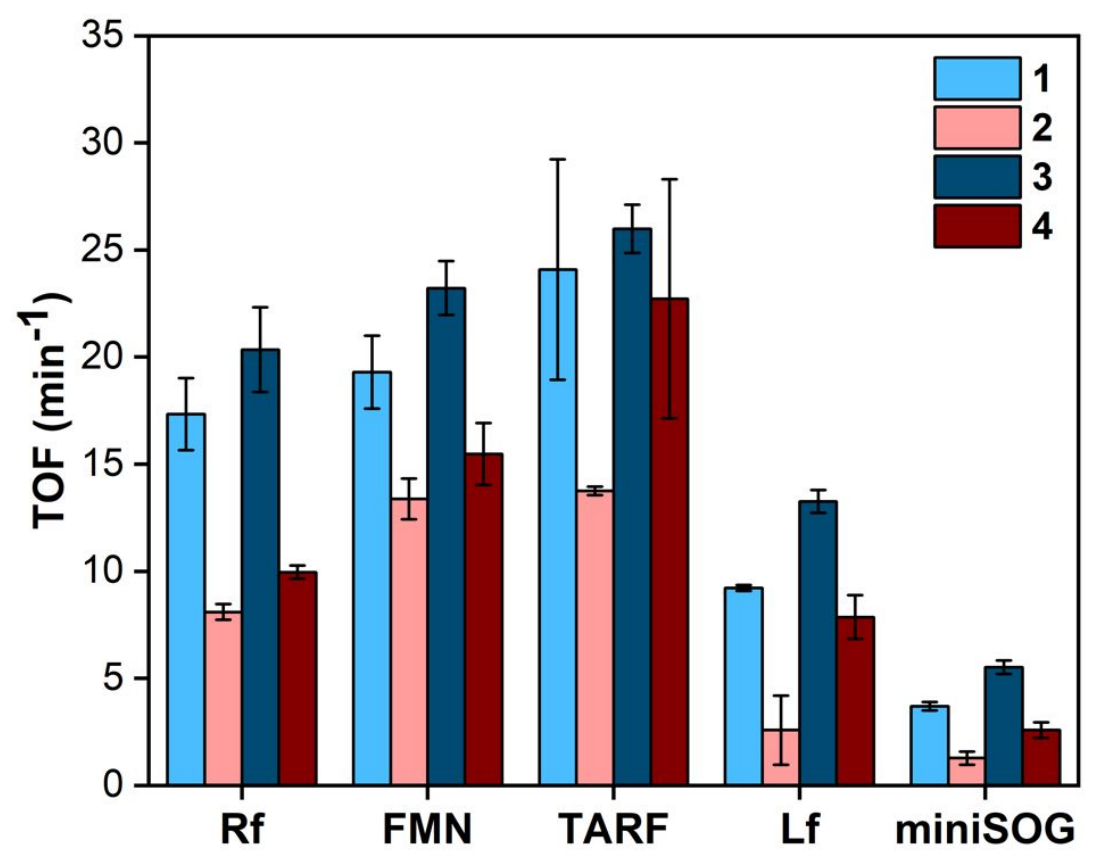

Figure 3. Turnover frequency values (TOF, $\mathrm{min}^{-1}$ ) for the flavin-catalyzed photoactivation of 1-4.

\section{Catalysis in cell culture medium}

The application of catalysis towards metal substrates in the context of medicinal inorganic chemistry relies on the capability of flavins to convert the $\mathrm{Pt}^{\mathrm{IV}}$ prodrugs in the biological environment, i.e. generate selectively $\mathrm{Pt}^{\prime \prime}$ species in cells and/or their surroundings. ${ }^{2,3}$ Therefore, we studied how the flavin catalysts performed the activation of Ptlv substrates in cell culture medium including fetal bovine serum (FBS). Such milieu contains a variety of chemicals and biological molecules that can interfere with the catalysis.

Substrates 1-4 were stable in medium containing $1 \mathrm{mM} \mathrm{NADH}$ for over $24 \mathrm{~h}$ in the dark (Figure S21). Upon addition of $\mathbf{R f}(25 \mu \mathrm{M})$ the substrates were instead slowly transformed into their reaction products without the need for light excitation. Reactions were slow, and less than $40 \%$ conversion was observed in the first $8 \mathrm{~h}$ (Figure S22). The behavior of the other flavin catalysts was studied using 1 and $\mathbf{4}$, because of their structural differences. In the dark, FMN and Lf performed similarly to Rf, promoting only partial substrate conversion at $8 \mathrm{~h}$ and full conversion at $24 \mathrm{~h}$ (Figure S23 and S24). TARF instead achieved full transformation of 1 and $\mathbf{4}$ within $1 \mathrm{~h}$ in the dark (Figure S25). Conversely, minisoG did not show the capacity to carry out the activation of the substrates ( $24 \mathrm{~h}$ ) in the absence of 
light (Figure S26), which is a potential advantage for controlling the effects associated with the activation of $\mathrm{Pt}^{\mathrm{IV}}$ prodrugs in cells.

Under light irradiation, all FLs were dramatically efficient in converting 1 and 4. For all catalysts, the $\mathrm{Pt}^{\mathrm{IV}}$ prodrugs were fully activated within $1 \mathrm{~min}$, except in the case of miniSOG which required more than 6-10 min (Figure S27 and S28). The quantification of reaction efficiencies was problematic in cell culture medium due to the crowded spectrum and signal overlapping. However, ${ }^{1} \mathrm{H}$ spectra evidenced that catalytic reactions were slightly faster than in buffer solutions, suggesting that catalysts were not noticeably inactivated in a more stringent biological environment and that they still recognized PtIV substrates despite the presence of numerous other chemical and biological reactants. Therefore, these results highlighted the bioorthogonal selectivity of flavin-mediated catalysis towards Pt substrates and indicated that other electron donors present in the medium likely contributed to the catalysis as well.

\section{Catalytic mechanism}

A plausible assumption for the mechanism of the $\mathrm{Pt}^{\mathrm{IV}}$-to- $\mathrm{Pt}^{\mathrm{I}}$ photocatalytic conversion of 1-4 implicates the formation of the triplet excited state $\left({ }^{3} \mathrm{FL}^{*}\right)$ of the flavin photocatalyst through intersystem crossing after exciting its singlet state. ${ }^{3} \mathrm{FL}^{*}$ is a strong oxidant capable of extracting 2 electrons from donors, such as $\mathrm{NADH}$, to afford $\mathrm{H}_{2} \mathrm{FL}$ or $\mathrm{HFL}^{-}$ depending on the $\mathrm{pH}$ of the solution. ${ }^{18}$ Such reduced flavin forms are the active catalytic species that prompt the effective and bioorthogonal transformation of 1-4 (Scheme 1). In the absence of light, the formation of $\mathrm{H}_{2} \mathrm{FL} / \mathrm{HFL}^{-}$still takes place but is significantly less efficient. Indeed, comparative experiments under $\mathrm{O}_{2}$-free conditions showed that the consumption of NADH by FMN is much slower in the dark than under irradiation (Figure S29-S31). Furthermore, reduced flavins are readily oxidized by $\mathrm{O}_{2}$ under aerobic conditions to ultimately give $\mathrm{H}_{2} \mathrm{O}_{2} \cdot{ }^{19}$ Thus, the conversion of $\mathrm{Pt}^{\mathrm{IV}}$ substrates is much slower in the absence of light, being $\mathrm{H}_{2} \mathrm{FL} / \mathrm{HFL}^{-}$present at lower concentrations. 


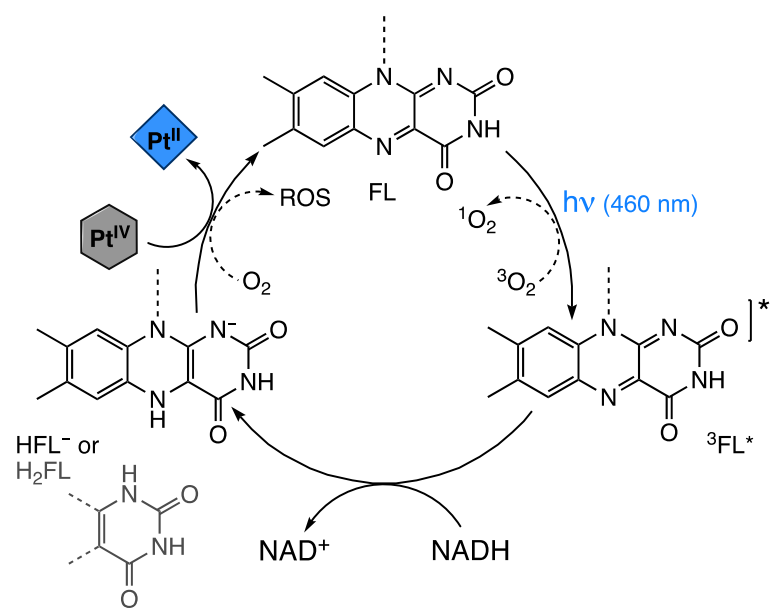

Scheme 1. Proposed mechanism for the catalytic conversion of substrates 1-4 by flavin catalysts.

To validate this mechanistic hypothesis, we studied in detail the reactivity of $\mathrm{H}_{2} \mathrm{FL} / \mathrm{HFL}^{-}$ towards 1 under oxygen-free conditions. $\mathrm{N}_{2}$-purged solution of FMN and NADH (1:1, 15 $\mu \mathrm{M}$ in $\mathrm{PB}, \mathrm{pH}$ 7.4) were irradiated at $460 \mathrm{~nm}$ for few seconds to obtain $\mathrm{HFMN}^{-}$as confirmed by the appearance of its characteristic absorption spectrum and the concomitant disappearance of FMN bands at $400-500 \mathrm{~nm}$ (Figure 4a). ${ }^{20}$ At pH above 7.0, HFL- is the most abundant species for the catalysts tested in this work. ${ }^{18}$ Nevertheless, experiments at different $\mathrm{pH}$, run using $\mathbf{1}$ and $\mathbf{3}$ and FMN indicated that both $\mathrm{H}_{2} \mathrm{FL}$ and $\mathrm{HFL}^{-}$could perform the catalysis with similar efficiency (Figure S14 and S32).

Of note, work by Hollmann ${ }^{21,22}$ demonstrated that light irradiation of flavin catalysts could boost reaction rates for the aerobic oxidation of reduced nicotinamide cofactors. Correspondingly, our results showed that use of NADH and visible light was effective in generating doubly reduced free flavins in oxygen free atmosphere. Compared to other established procedures, ${ }^{23}$ this approach is advantageous since it avoids the use of high concentrations of strong reductants (e.g. sodium dithionite or borohydride) or the need of long photoreduction reactions with oxalate and UV light.

We obtained proof that HFMN $^{-}$is the catalytic active species by monitoring the evolution of its UV-Vis spectrum upon addition of 1 ( $54 \mu \mathrm{M}$, final concentration) under anaerobic conditions. As shown in Figure $4 \mathrm{a}$, $\mathbf{H F M N}^{-}$was promptly re-oxidized and the absorption features of FMN restored once the $\mathrm{Pt}^{\mathrm{I}} \mathrm{V}$ substrate was added. Under similar conditions (i.e. no $\mathrm{O}_{2}, 3.3 \mathrm{mM}$ FMN and NADH, PB, pH 7.4), ${ }^{1} \mathrm{H}$ NMR resonances of FMN disappeared in the presence of $\mathrm{NADH}$ upon light irradiation (Figure $4 \mathrm{~b}$ ), consistently with the conversion to $\mathrm{HFMN}^{-}$, and reemerged only after successive additions of $\mathbf{1}$ (4 mM, final concentration). The presence of the singlet signal correspondent to free succinate confirmed the 
conversion of the $\mathrm{Pt}^{\mathrm{IV}}$ substrate. Once an excess of substrate was added (Figure 4b), signals relative to unreacted 1 became clearly visible again. As previously reported by Gschwind and coworkers, ${ }^{24,25}$ line broadening due to proton exchange prevented direct detection of ${ }^{1} \mathrm{H}$ NMR signals relative to reduced flavin species in aqueous solutions. Equivalent results were obtained by UV-Vis for TARF and Lf using 1 as substrate (Figure S33 and S34).
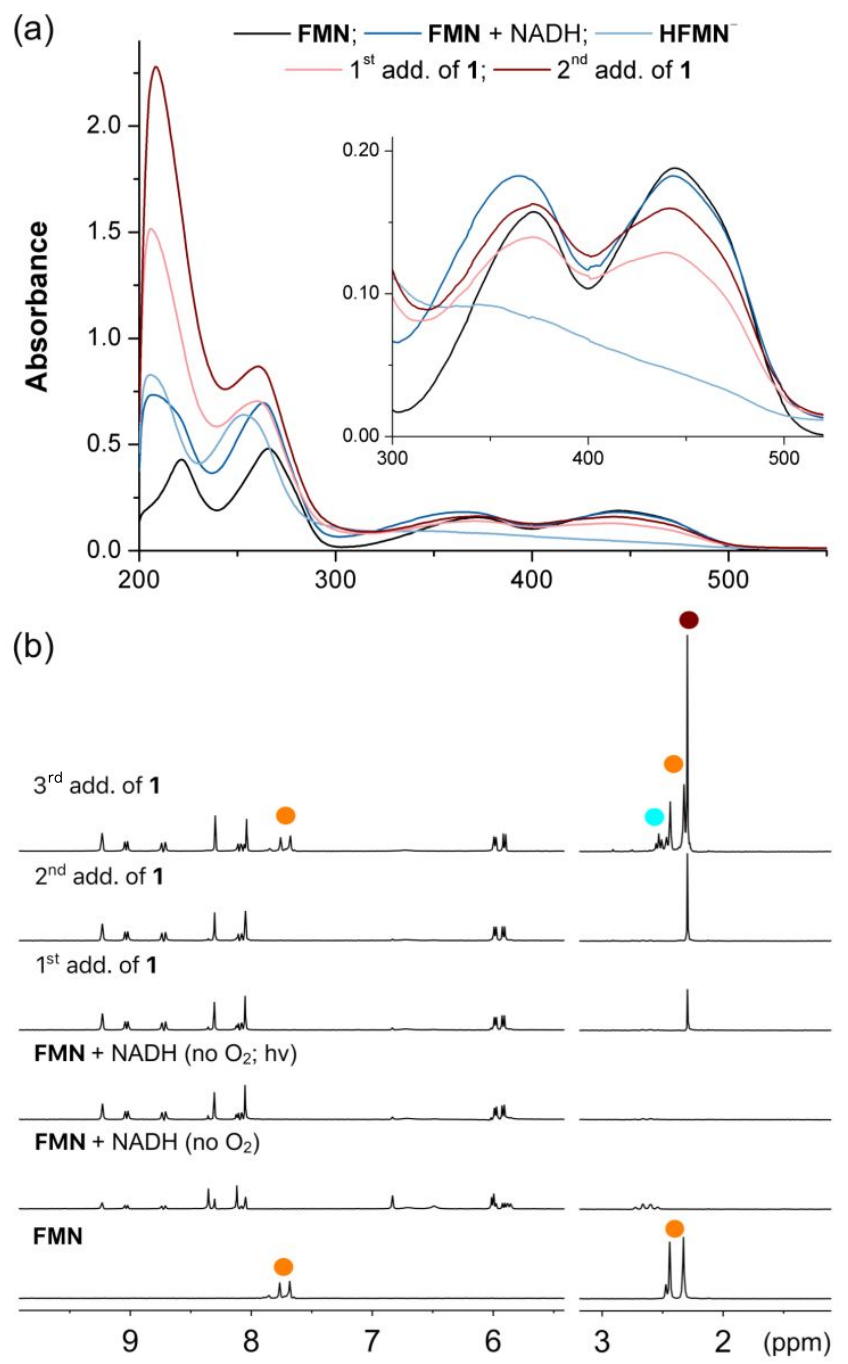

Figure 4. (a) UV-Vis and (b) NMR characterization of the key catalytic species HFMN' $^{-}$and its reactivity towards 1. HFMN $^{-}$(a: $15 \mu \mathrm{M}$; b: $3.3 \mathrm{mM}$ ) generated using 1 mol equiv. of NADH upon 460-nm light irradiation $\left(6 \mathrm{~mW} \cdot \mathrm{cm}^{-2}\right.$, a: $\left.40 \mathrm{~s} ; \mathrm{b}: 360 \mathrm{~s}\right)$ in the absence of $\mathrm{O}_{2}(18 \mathrm{mM}$ PB, $\mathrm{pH}$ 7.4). Final concentrations of 1 were 54 $\mu \mathrm{M}$ and $4 \mathrm{mM}$ for UV-Vis and NMR experiments, respectively. ${ }^{1} \mathrm{H}$ NMR signal labelling: $\bullet \mathrm{FMN}$; $\bullet$ free $\mathrm{O}_{2} \mathrm{CCH}_{2} \mathrm{CH}_{2} \mathrm{CO}_{2}^{-} ; \circ \mathbf{1}\left(\mathrm{Pt}-\mathrm{OCO} \mathrm{CH}_{2} \mathrm{CH}_{2} \mathrm{CO}_{2}^{-}\right)$.

Time-resolved optical spectroscopy proved that generation of $\mathrm{HFL}^{-}$occurred via initial reductive quenching of the ${ }^{3} \mathrm{FL}^{*}$ excited state by $\mathrm{NADH}$. In first instance, fluorescence emission lifetime measurements performed on FMN $\left(\lambda_{\text {exc }}=445 \mathrm{~nm}, \lambda_{\text {em }}=540 \mathrm{~nm}\right.$, Figure $\mathrm{S} 35)$ indicated that its singlet excited state decay $\left(\mathrm{T}_{\mathrm{Fluo}}=4.7 \mathrm{~ns}\right.$ ) was not altered by the 
presence of NADH (1:20) or NADH and 1 (1:20:20), therefore ruling out the involvement of such state in the catalytic process. However, the case for the ${ }^{3} \mathbf{F M N}^{*}$ excited state was different, as demonstrated by flash photolysis experiments (Figure 5, Figure S36). Previous work ${ }^{26}$ showed that the evolution of the triplet state of $\mathbf{R f}$ in the presence of quenchers can be monitored by the decay of its characteristic triplet-triplet absorption band. For this reason, we measured the transient absorption spectrum of FMN $\left(\lambda_{\text {exc }}=445\right.$ $\mathrm{nm}$ ) in a de-aerated solution and determined the triplet lifetime in the presence of NADH and 1 . Consistently with the literature, ${ }^{3} \mathbf{F M N}^{*}$ displayed an intense and negative contribution in the $420-480 \mathrm{~nm}$ range, corresponding to the ground state bleaching associated with the $S_{0} \rightarrow S_{1}$ transition. The positive band at around 600-720 nm was attributed to the absorption of the $T_{1}$ state. The assignation of the triplet-state absorption was also confirmed by its quenching in the presence of $\mathrm{O}_{2}$. The FMN triplet lifetime in a de-aerated solution $\left(\mathrm{T}_{0}^{\top}\right.$ ) was $14 \mu \mathrm{s}$ (Figure 5 ) long enough for an efficient quenching by $\mathrm{O}_{2}$, which indeed reduced $\mathrm{T}^{\top}$ to $4 \mu \mathrm{s}$ in air-saturated samples (Figure S36). In the presence of an NADH excess (1:20), we observed that $\mathrm{T}_{0}{ }^{\top}$ decreased as well, from $14 \mu \mathrm{s}$ to $2.3 \mu \mathrm{s}$, confirming the reductive quenching of ${ }^{3} \mathrm{FMN}^{*}$ by this electron donor. Nevertheless, no further significant changes were observed on $\mathrm{T}_{0}{ }^{\top}$ once 1 (1:20:20) was added to the solution containing both FMN and $\mathrm{NADH}$. This result indicated that the $\mathrm{Pt}^{\mathrm{IV}}$ conversion process does not involve ${ }^{3} \mathrm{FMN}^{*}$, but rather the ground-state $\mathbf{H F M N}^{-}$species in agreement with UV-Vis and NMR data (Figure 4). Similar findings were obtained tracking the triplet excited state decay in air saturated solutions (Figure S36).

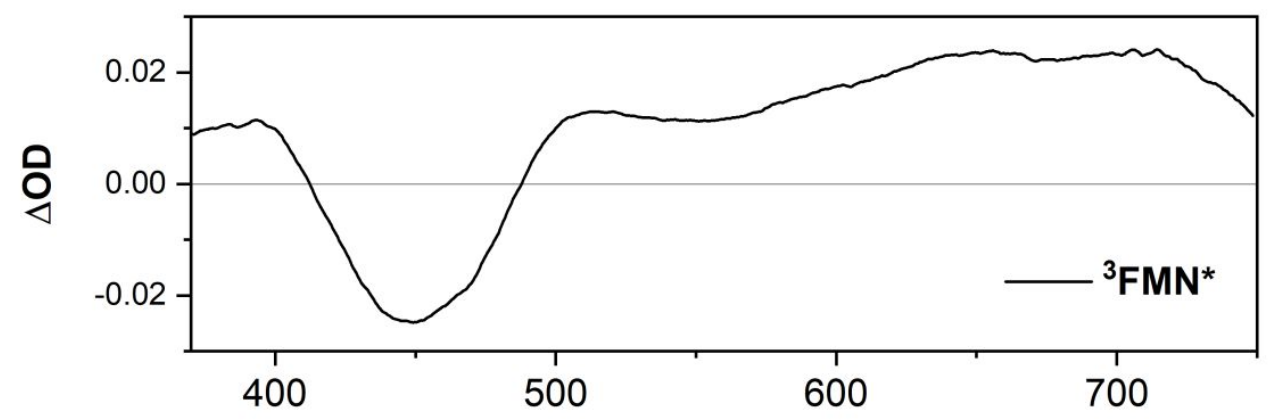

Wavelength (nm)
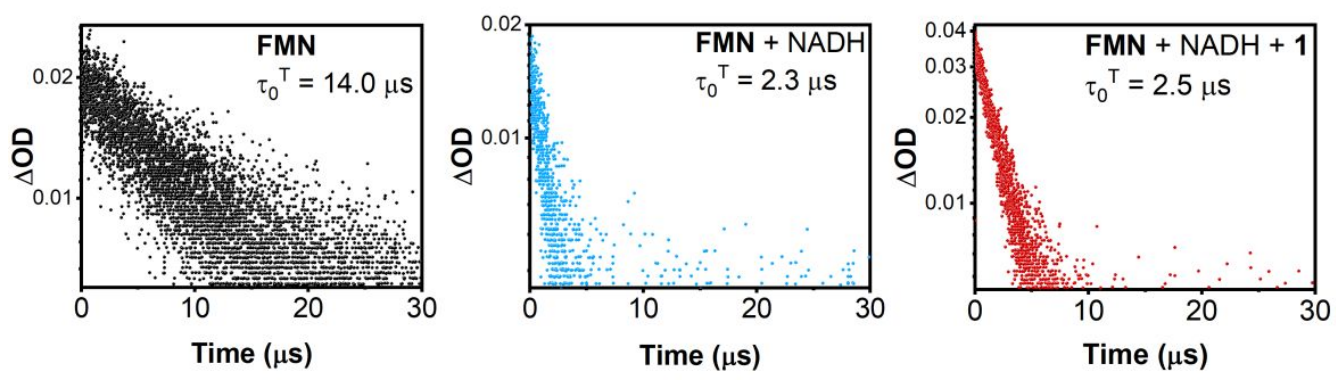
Figure 5. Transient absorption spectrum $\left(\lambda_{\text {exc }} 445 \mathrm{~nm}\right.$ ) of ${ }^{3} \mathrm{FMN}^{*}$ and decays $\left(\mathrm{T}_{0}{ }^{\top}\right)$ of the triplet-triplet absorption at $700 \mathrm{~nm}$ for $\mathrm{N}_{2}$-deareated solutions of FMN $(20 \mu \mathrm{M})$, FMN $(20 \mu \mathrm{M})+\mathrm{NADH}(400 \mu \mathrm{M})$, and FMN $(20 \mu \mathrm{M})+\mathrm{NADH}(400 \mu \mathrm{M})+1(400 \mu \mathrm{M})$.

Considering that reduction potentials for 1-4 are more negative (Figure S37) than FLs, an outer sphere reduction of the substrates would be a neat uphill reaction. For this reason, formation of substrate- $\mathrm{H}_{2} \mathrm{FL} / \mathrm{HFL}^{-}$intermediates, and possibly a ligand-bridged inner sphere mechanism, might promote the flavin-mediated reduction of $\mathrm{Pt}^{\mathrm{IV}}$ complexes. ${ }^{27}$ These adducts could trigger the conversion of 1-4 in to their $\mathrm{Pt}^{\|}$counterparts at a less negative potential. ${ }^{12}$ Furthermore, specific catalyst-substrate interactions could also explain the bioorthogonal selectivity of these reactions.

Density functional theory (DFT) calculations indicated that such a scenario is reasonable. Indeed, we optimized a number of substrate- $\mathrm{H}_{2} \mathbf{R f} / \mathrm{HRf}^{-}$adducts stabilized by hydrogen bonding interactions between the ligands of the Pt complexes and the isoalloxazine and ribityl moieties of FLs (Figure 6, Figure S38 and S39). Consistently with the occurrence of reduction and ligand elimination reactions, optimized geometries displayed electronic structures in which the HOMO (highest occupied molecular orbital) is centered on $\mathrm{H}_{2} \mathbf{R f} / \mathrm{HRf}^{-}$, while the LUMO (lowest unoccupied molecular orbital) and LUMO+1 are $\sigma$ antibonding orbitals localized on 1-4 (Figure S40-42). All optimized structures showed interactions of the Pt-bound ligands with the ribityl chain, confirming that lack of this fragment was consistent with a decrease in catalytic activity as observed for Lf towards all substrates (Table 1 and Figure 3). Furthermore, DFT highlighted that $\mathrm{H}$-bonding between TARF and the substrates were still possible, despite the acetylated ribityl chain of this catalyst. In particular, we could optimize adduct geometries in which the $\mathrm{NH}_{3}$ ligand of 14 formed $\mathrm{H}$-bonds with the $\mathrm{C}=\mathrm{O}\left(2^{\prime} \mathrm{C}\right)$ of the ribityl and/or the $\mathrm{N}(5)$ of the isoalloxazine unit of TARF (Figure S43).

The overall lower conversion efficiency for the carboplatin derivatives 2 and 4 compared to their cisplatin counterparts $\mathbf{1}$ and $\mathbf{3}$ could instead be ascribed to the intrinsic thermodynamic stability of the $\mathrm{Pt}$ complexes. In fact, the corresponding axial and equatorial ligand exchange energy, calculated with different DFT functionals (Figure S44), indicated that 1 and $\mathbf{3}$ are less stable than $\mathbf{2}$ and $\mathbf{4}$, respectively. The same holds true for succinato versus acetato ligands, having $\mathbf{3}$ lower stability than $\mathbf{1}$ and $\mathbf{4}$ than $\mathbf{2}$. These trends are also in good agreement with reduction potentials of the complexes (Figure S37). 

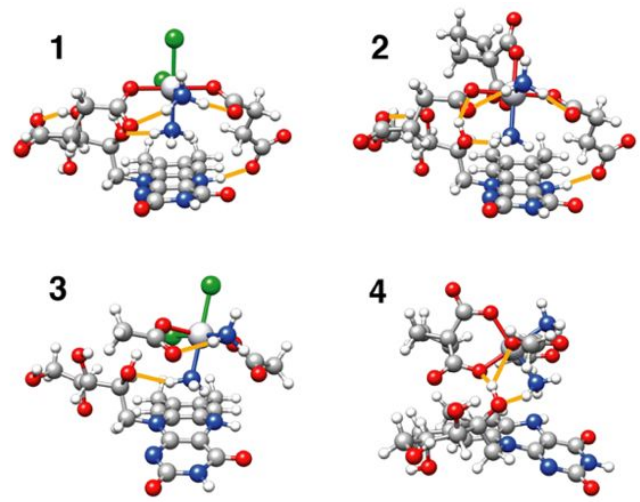

Figure 6. DFT-optimized (pbe0/def2-SVP) structures of adducts between 1-4 and $\mathbf{~ f f H}^{-}(\mathrm{H}$-bond contacts highlighted with orange lines).

In order to further rationalize the lower stability of cisplatin derivatives with respect to carboplatin ones, we also analyzed the DFT atomic charge of the Pt atom in 1-4 and their corresponding $\mathrm{Pt}^{\mathrm{Il}}$ drugs. Irrespective of the functional or the atomic charge evaluation method used, the Pt atom showed a significant lower positive charge in cisplatin than in carboplatin, as well as in their corresponding PtIV prodrugs (Figure S37). Therefore, the electrostatic interaction between the Pt center and its equatorial ligands is weaker in the case of cisplatin derivatives compared to carboplatin complexes, and consequently 1 and $\mathbf{3}$ are more easily converted than $\mathbf{2}$ and $\mathbf{4}$. On the other hand, since succinato ligands bear a doubly negative charge at neutral $\mathrm{pH}\left(\mathrm{pK}_{\mathrm{a} 1}=4.2\right.$ and $\left.\mathrm{pK}_{\mathrm{a} 2}=5.6\right)$, whereas acetato ligands $\left(\mathrm{pK}_{\mathrm{a}}=5.5\right)$ are only singly negatively charged, the Pt-acetato bond is weaker than the Pt-succinato one, and therefore easier to activate. These stability trends for 1-4 can be traced back to the stabilization of the Pt-ligand bonds, and provide an overall good explanation for the different prodrug conversion efficiencies found in this work.

MiniSOG has an FMN embedded in the protein structure and showed a more intricated photochemistry. Upon light irradiation and in the absence of electron donors and $\mathrm{O}_{2}$, miniSOG generated the $\mathrm{FMN}^{-}$- radical (semiquinone) that displayed a broad absorption peak at ca. $600 \mathrm{~nm}$ (Figure S46). This process was previously ascribed to the oxidation of certain amino acids and is known to compete with the capacity of miniSOG to generate ${ }^{1} \mathrm{O}_{2}$ with high yields. ${ }^{28-30}$ Upon exposing irradiated solutions of minisog to the oxygencontaining ambient atmosphere, the spectral features of $\mathrm{FMN}^{--}$disappeared and the absorbance at $450 \mathrm{~nm}$ was almost completely recovered (Figure S46). Conversely, 1 poorly reacted with the radical when incubated with miniSOG. This effect was observed by UV-Vis and ${ }^{1} \mathrm{H}$ NMR experiments (Figure S47 and S48), in which stochiometric quantities 
of light-irradiated miniSOG in the absence of $\mathrm{O}_{2}$ could transform 1 much slower than under the standard aerobic catalysis conditions.
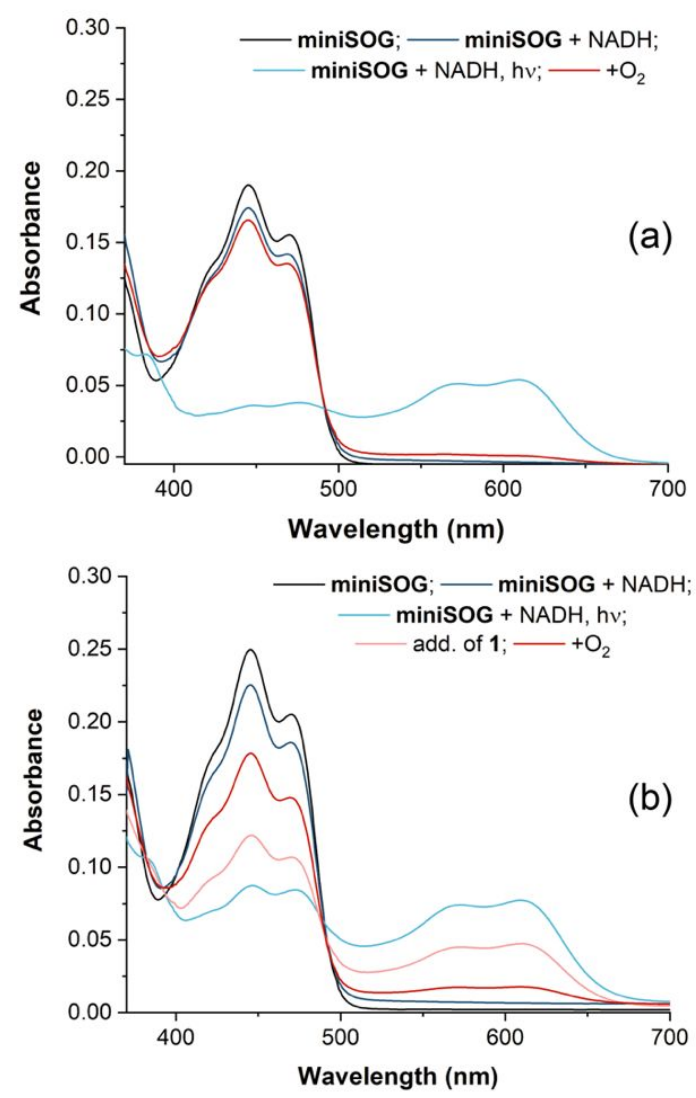

Figure 7. UV-Vis monitoring of light-irradiated miniSOG under anaerobic conditions upon addition of electron acceptors: (a) $\mathrm{O}_{2}$ and (b) $1(120 \mu \mathrm{M})$. Solutions of miniSOG $(15 \mu \mathrm{M}, 18 \mathrm{mM}$ PB, pH 7.4) were irradiated (6 $\mathrm{mW} \cdot \mathrm{cm}^{-2}, 180 \mathrm{~s}$ ) in the presence of $1 \mathrm{~mol}$ equiv. of $\mathrm{NADH}$ and in the absence of $\mathrm{O}_{2}$.

In the presence of $\mathrm{NADH}$, electron transfer from the protein scaffold was not shut down and the FMN $^{-}$- radical could still be detected (Figure $7 \mathrm{a}$ and b). Nevertheless, UV-Vis spectra revealed that doubly-reduced FMN was also obtained, as indicated by the marked absorbance decrease at 400-500 nm. Exposure of such solution to either $\mathrm{O}_{2}$ or 1 (120 $\mu \mathrm{M}$ ) caused the regeneration of FMN indicating that $\mathrm{HFMN}^{-}$was likely the major active catalytic species towards the Pt substrates for miniSOG as well. So, quenching of FMN excited state by photooxidation of amino acid residues competed with the formation of the active catalysts, in a similar fashion to what has been observed for ${ }^{1} \mathrm{O}_{2}$ sensitization. Compared to other FLs tested herein, the lower conversions and TOF values of miniSOG should also be ascribed to the reduced substrate accessibility of its FMN.

As shown here for miniSOG and for other FL catalysts in Figure $\mathrm{S} 49, \mathrm{O}_{2}$ functioned as electron sink to deactivate doubly and singly-reduced FLs. This behavior is not surprising considering the biochemistry of flavins and flavoproteins. However, it suggests that the 
role of $\mathrm{O}_{2}$ in the catalytic conversion of 1-4 ought to be evaluated for a thorough comprehension of the catalytic mechanism. In addition, FLs such as the one tested in this work are well known singlet-oxygen $\left({ }^{1} \mathrm{O}_{2}\right)$ photosensitizers. ${ }^{13,31}$

Monitoring the photoactivation kinetics of 1-4 in aerated solutions, we observed an induction period for all FL catalysts (Figure S50) at short light irradiation times. This finding is consistent with the presence of competitive catalytic cycles that involve the transformation of $\mathrm{O}_{2}$ in ${ }^{1} \mathrm{O}_{2}$ and reactive oxygen species (ROS). Under anaerobic conditions, conversion of substrates readily occurs. Conversely, as shown for 1 and FMN (Figure S51), the reaction does not reach completion and kinetics is significantly slower when air is bubbled into the solution.

FL catalysts can interact with $\mathrm{O}_{2}$ in the ${ }^{3} \mathrm{FL}^{*}$ excited state to give ${ }^{1} \mathrm{O}_{2}$ or once reduced to $\mathrm{HFL}^{-}$to generate ROS such as $\mathrm{O}_{2}{ }^{--}$and $\mathrm{H}_{2} \mathrm{O}_{2}$ (Scheme 1). We confirmed the occurrence of both pathways by means of indirect optical methods previously validated for FMN and miniSOG. ${ }^{12,29}$ That is, we employed uric acid and hydroethidine as molecular probes for the formation of ${ }^{1} \mathrm{O}_{2}$ and ROS, respectively. We observed that FMN and miniSOG solutions irradiated in the presence of an excess of NADH and 1 showed indeed production of both (Figure S52-S54). As described previously, ${ }^{12,29}$ free $\mathbf{F M N}$ is a better ${ }^{1} \mathrm{O}_{2}$ photosensitizer than FMN embedded in the miniSOG scaffold, in agreement with the self-quenching of its triplet excited state by the protein matrix in the latter case. However, minisog generation of ROS was almost comparable to $\mathrm{FMN}$, reasonably because $\mathrm{O}_{2}{ }^{--}$is readily formed by photoinitiated electron-transfer reactions involving the protein (e.g. from $\mathrm{FMN}^{\bullet-}$ ). Control experiments run in the absence of NADH and 1 did not show a significant decrease in the generation of ${ }^{1} \mathrm{O}_{2}$ and ROS, suggesting that $\mathrm{O}_{2}$ was immediately converted by flavins in such photoproducts, before the catalysis towards Pt substrates took place.

\section{CONCLUSIONS}

This work expands the scope of flavin-mediated photocatalysis towards platinum substrates, providing new fundamental mechanistic details. The reduced $\mathrm{H}_{2} \mathrm{FL} \mathrm{HFL}^{-}$ species has been identified by optical spectroscopy and NMR under anaerobic conditions as the active catalyst. $\mathrm{H}$-bond interactions between $\mathrm{H}_{2} \mathrm{FL} / \mathrm{HFL}^{-}$and the $\mathrm{Pt}^{\mathrm{IV}}$ substrates may be crucial in promoting the conversion to $\mathrm{Pt}$ "l drugs, possibly via a ligand-bridged inner sphere reduction mechanism. The ribityl chain could stabilize these putative intermediates and increase the catalytic efficiency of the reactions. For this reason, Lf showed the lowest TOFs among the free FLs tested. Self-quenching of the minisoG 
excited states by protein amino acids reduced the efficiency of this catalyst, as similarly observed for its ${ }^{1} \mathrm{O}_{2}$ photosensitization capacity. Structural modifications of the ribityl group in free FLs and site mutagenesis in miniSOG are worth investigating in the future to boost their catalytic activity and widen the repertoire of this new chemistry towards different metals.

\section{EXPERIMENTAL SECTION Materials}

Riboflavin (Rf), riboflavin 5'-monophosphate sodium salt hydrate (FMN), potassium phosphate monobasic, potassium phosphate dibasic, $\beta$-nicotinamide adenine dinucleotide, reduced disodium salt hydrate, sodium dithionite, RPMI-1640 medium were purchased from Sigma-Aldrich, potassium tetrachloroplatinate(II) from Precious Metals Online. All chemicals were used as received without additional purification. The fetal bovine serum (10\%) added to the RPMI-1640 medium was purchased from Invitrogen.

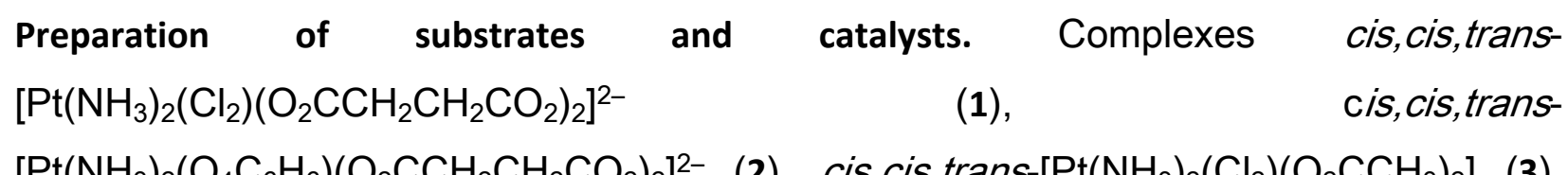
$\left[\mathrm{Pt}\left(\mathrm{NH}_{3}\right)_{2}\left(\mathrm{O}_{4} \mathrm{C}_{6} \mathrm{H}_{6}\right)\left(\mathrm{O}_{2} \mathrm{CCH}_{2} \mathrm{CH}_{2} \mathrm{CO}_{2}\right)_{2}\right]^{2-}$ (2), cis, cis, trans-[Pt $\left.\left(\mathrm{NH}_{3}\right)_{2}\left(\mathrm{Cl}_{2}\right)\left(\mathrm{O}_{2} \mathrm{CCH}_{3}\right)_{2}\right]$ (3), cis, cis, trans- $\left[\mathrm{Pt}\left(\mathrm{NH}_{3}\right)_{2}\left(\mathrm{O}_{4} \mathrm{C}_{6} \mathrm{H}_{6}\right)\left(\mathrm{O}_{2} \mathrm{CCH}_{3}\right)_{2}\right]$ (4) were synthesized and characterized as previously reported. ${ }^{32-34}$ Tetra-O-acetyl riboflavin (TARF) and lumiflavin (Lf) were prepared following the procedure reported by I. Jhulki et al. ${ }^{35}$ MinisoG was prepared and purified as previously reported by us. ${ }^{3}$

\section{Methods}

Nuclear magnetic Resonance (NMR). ${ }^{1} \mathrm{H}$ NMR spectra of the various samples were recorded on a Fourier TM Bruker 300 NMR and on an AVANCE III Bruker 500 NMR spectrometer using standard pulse programs. Chemical shifts were reported in parts-per-million $(\delta$, ppm) and referenced to the residual solvent peak.

Catalysis experiments. Unless otherwise specified, all reactions were carried out in air at $298 \mathrm{~K}$ and $\mathrm{pH} 7.0$ using $25 \mu \mathrm{M}$ catalyst, $500 \mu \mathrm{M}$ substrate (1-4) and $1 \mathrm{mM} \mathrm{NADH}$. Light irradiation experiments were performed employing an LED light source $\left(\lambda_{\max }=460 \mathrm{~nm}, 6\right.$ $\left.\mathrm{mW} \cdot \mathrm{cm}^{-2}\right) \cdot{ }^{4}$ Turnover frequency (TOF), turnover number (TON) and \% conversion for the catalytic reactions were determined by quantifying the amount of converted $1-4$ via ${ }^{1} \mathrm{H}$ 
NMR. Integration of the free succinato and acetato ligand signals (singlets at 2.25-2.35 ppm and at approx. 1.80 ppm respectively) were used for monitoring the reaction progress. TOF values were obtained at substrate conversions of $25-35 \%$.

UV-Vis absorption spectroscopy (UV-Vis). All spectra were acquired in optical quartz cuvettes in aqueous solutions or buffers using a JASCO V-730 spectrophotometer.

Fluorescence emission and lifetimes. The emission spectrum of FMN $(20 \mu \mathrm{M})$ was recorded on a spectrofluorimeter Edinburgh Instruments (FL920 model) with a $450 \mathrm{~W}$ xenon flash lamp as the excitation source. Fluorescence radiative decay curves were recorded with a time-correlated single-photon counting technique (Edinburgh Instruments, model FL920) at $\lambda_{\mathrm{em}}=540 \mathrm{~nm}$ after excitation at $\lambda_{\mathrm{exc}}=445 \mathrm{~nm}$ by means of a fianium supercontinuous wavelength tunable-laser with 150 ps FWHM pulses using a microchannel plate detector (Hamamatsu C4878) with picosecond time resolution. Fluorescence lifetimes were obtained after deconvolution of the instrumental response signal from the recorded decay curves by means of an iterative method. The goodness of the exponential fit was controlled by statistical parameters ( $X^{2}$ and analysis of the residuals). Measurements were performed on air-saturated solutions of (a) FMN (20 $\mu \mathrm{M})$, (b) FMN $(20 \mu \mathrm{M})$ and NADH (400 $\mu \mathrm{M})$, and (c) FMN $(20 \mu \mathrm{M}), \mathrm{NADH}(400 \mu \mathrm{M})$ and $1(400 \mu \mathrm{M})$.

Transient absorption and triplet lifetimes. Nanosecond transient absorption measurements were recorded on a LP980 laser flash photolysis spectrometer (Edinburgh Instruments, Livingston, UK). Samples were excited by a nanosecond pulsed laser (Nd:YAG laser/OPO, LOTIS TII 2134) at the absorption maxima (445 nm) operating at $1 \mathrm{~Hz}$ and with a pulse width of $7 \mathrm{~ns}$ at a $10 \mathrm{~mJ}$ excitation power. Samples with an optical absorbance of 0.3 at the excitation wavelength were either deaerated with nitrogen for ca. 10 min or aerated for ca. 10 min with air. Transient spectra were recorded on ICCD detector (DH320T TE cooled, Andor Technology). The decay of triplet-triplet absorption in the presence and absence of oxygen (nitrogen and air saturated solutions) were collected at $700 \mathrm{~nm}$ on single detector (PMT R928P) and oscilloscope. Triplet lifetimes in absence and presence of oxygen $\left(\mathrm{T}_{0}{ }^{\top}\right.$ and $\left.\mathrm{T}^{\top}\right)$ were obtained from the slope of the recorded decay curves by means of an iterative method by LP900 software. The goodness of the exponential fit was controlled by statistical parameters $\left(X^{2}\right)$. Solutions of (a) FMN $(20 \mu M)$, 
(b) FMN $(20 \mu \mathrm{M})$ and NADH $(400 \mu \mathrm{M})$, and (c) FMN $(20 \mu \mathrm{M})$, NADH $(400 \mu \mathrm{M})$ and $1(400$ $\mu \mathrm{M})$ were employed for in this set of experiments.

Singlet oxygen and ROS production. Quantification of ${ }^{1} \mathrm{O}_{2}$ and ROS was achieved using methods previously established for FMN and minisoG. ${ }^{12,29}$ Indirect measurement of ${ }^{1} \mathrm{O}_{2}$ was performed using uric acid (UA) as probe ${ }^{36}$ and monitoring the changes of its absorbance at $292 \mathrm{~nm}$ over light irradiation time. We exposed to $460-\mathrm{nm}$ light $\left(6 \mathrm{~mW} \cdot \mathrm{cm}^{-2}\right)$ optically-matched solutions containing UA $(50 \mu \mathrm{M})$ and (a) FMN/minisOG $(5 \mu \mathrm{M})$, (b) FMN/minisOG $(5 \mu \mathrm{M})$ and NADH $(30 \mu \mathrm{M})$, and (c) FMN/minisOG $(5 \mu \mathrm{M}), \mathrm{NADH}(30 \mu \mathrm{M})$ and $1(15 \mu \mathrm{M})$.

Photooxidation of hydroethidine (HE) was instead used to evaluate the production of other ROS (particularly $\mathrm{O}_{2}^{--}$) since the transformation of this probe does not occur upon interaction with ${ }^{1} \mathrm{O}_{2} \cdot{ }^{29,37}$ Also in this case, $\mathrm{HE}(50 \mu \mathrm{M})$ solutions containing (a) FMN/minisOG (5 $\mu \mathrm{M})$, (b) FMN/miniSOG (5 $\mu \mathrm{M})$ and NADH (30 $\mu \mathrm{M})$, and (c) FMN/minisOG $(5 \mu \mathrm{M}), \mathrm{NADH}(30 \mu \mathrm{M})$ and $1(15 \mu \mathrm{M})$ were irradiated at $460 \mathrm{~nm}$ and their fluorescence intensity collected at different time points $\left(\lambda_{\mathrm{ex}}=525 \mathrm{~nm}, \lambda_{\mathrm{em}}=550-800 \mathrm{~nm}\right)$ as described previously. ${ }^{29}$

Electrochemistry. Cyclic voltammetry experiments were performed using a Metrohm Autolab $302 \mathrm{~N}$ potentiostat. The electrochemical cell was a single-compartment cell equipped with a standard three-electrode set-up: a glassy carbon working electrode $(\varnothing=$ $1 \mathrm{~mm}$ ), a Pt-wire counter electrode and and a saturated calomel electrode (SCE) as reference. All measurements were carried out in deoxygenated condition under argon atmosphere, employing a $0.05 \mathrm{M}$ phosphate buffer $(\mathrm{pH} 7.4)$ containing $0.15 \mathrm{M} \mathrm{NaCl}$. Solutions for metal complexes were $5.0 \cdot 10^{-4} \mathrm{M}$. FMN and Rf were measured at $2.7 \cdot 10^{-4}$ and $2.0 \cdot 10^{-4} \mathrm{M}$ respectively, while TARF and Lf voltammogram were obtained using saturated solutions due to poor solubility. The working electrode was polished with alumina, rinsed with distilled water and dried before each potential sweep to ensure reproducible surface for all experiments.

Computational methods. All calculations were performed with Gaussian 16, Revision B01. ${ }^{38}$ Geometry optimizations of substrate-riboflavin adducts were run at the DFT level using the pbe0/def2-SVP combination. ${ }^{39,40}$ Solvent was introduced by means of the polarized continuum model (PCM) with water as implicit solvent, and dispersion 
interactions were taken into account using Grimme's dispersion correction with Becke and Johnson's damping. ${ }^{41}$ The frequencies were then used to evaluate the zero-point vibrational energy (ZPVE) and the thermal $(T=298 \mathrm{~K}$ ) vibrational corrections to the enthalpies and Gibbs free energies within the harmonic oscillator approximation. To calculate the entropy, the different contributions to the partition function were evaluated using the standard statistical mechanics expressions in the canonical ensemble and the harmonic oscillator and rigid rotor approximation. Energy calculations for the relative stability of substrates 1-4 were performed using the def2-TVP basis $\operatorname{set}^{40}$ and three different functionals, namely pbe0, wb97xd $\mathrm{w}^{42}$ and $\mathrm{m062x} .{ }^{43}$ We calculated atomic charges using the same combination of functionals and basis set together with the $\mathrm{nbo}^{44}$ and chelpg 45 methods.

\section{AUTHOR INFORMATION \\ Corresponding Author \\ E-mail*: Isalassa@dipc.org}

\section{ORCID}

Virginia Martínez-Martínez: 0000-0001-7551-3714

Claudio Garino: 0000-0002-7854-6076

Fabrizio Mancin: 0000-0003-0786-0364

Aitziber L. Cortajarena: 0000-0002-5331-114X

Luca Salassa: 0000-0002-2112-9095

\section{Notes}

The authors declare no competing financial interest.

\section{ASSOCIATED CONTENT}

The Supporting Information is available free of charge on the ACS Publications website at DOI:XXXX.

Stability and catalysis experiments (NMR and UV-Vis), electrochemistry, time-resolved spectroscopy data and DFT results.

\section{ACKNOWLEDGMENTS}

We acknowledge financial support from the Spanish MINECO (grant CTQ2016-80844-R, BIO2016-77367-R, PCI2018-092984 and MAT2017-83856-C3-3-P), Eusko Jaurlaritza 
(Elkartek KK-2017/00008, IT588-13 and IT912-16), UPV/EHU (PES14/35), and the European Research Council (ERC-CoG-648071). This work was performed under the Maria de Maeztu Units of Excellence Program from the Spanish State Research Agency - Grant No. MDM-2017-0720 (CIC biomaGUNE). We thank Dr. Á. Martínez for support in the synthesis of TARF and Lf. Authors acknowledge the technical and human support provided by the IZO-SGI SGIker of UPV/EHU.

\section{REFERENCES}

(1) Alonso-de Castro, S.; Terenzi, A.; Gurruchaga-Pereda, J.; Salassa, L. Catalysis Concepts in Medicinal Inorganic Chemistry. Chem. - A Eur. J. 2019, 25, 6651-6660. https://doi.org/10.1002/chem.201806341.

(2) Alonso-de Castro, S.; Terenzi, A.; Hager, S.; Englinger, B.; Faraone, A.; Martínez, J. C.; Galanski, M.; Keppler, B. K.; Berger, W.; Salassa, L. Biological Activity of PtIV Prodrugs Triggered by Riboflavin-Mediated Bioorthogonal Photocatalysis. Sci. Rep. 2018, 8, 17198. https://doi.org/10.1038/s41598-018-35655-2.

(3) Alonso-de Castro, S.; Cortajarena, A. L.; López-Gallego, F.; Salassa, L. Bioorthogonal Catalytic Activation of Platinum and Ruthenium Anticancer Complexes by FAD and Flavoproteins. Angew. Chemie Int. Ed. 2018, 57, 31433147. https://doi.org/10.1002/anie.201800288.

(4) Alonso-de Castro, S.; Ruggiero, E.; Ruiz-de-Angulo, A.; Rezabal, E.; MarequeRivas, J. C.; Lopez, X.; López-Gallego, F.; Salassa, L. Riboflavin as a Bioorthogonal Photocatalyst for the Activation of a Pt'V Prodrug. Chem. Sci. 2017, 8, 4619-4625. https://doi.org/10.1039/C7SC01109A.

(5) Ngo, A. H.; Bose, S.; Do, L. H. Intracellular Chemistry: Integrating Molecular Inorganic Catalysts with Living Systems. Chem. - A Eur. J. 2018, 24, 10584-10594. https://doi.org/10.1002/chem.201800504.

(6) Martínez-Calvo, M.; Mascareñas, J. L. Organometallic Catalysis in Biological Media and Living Settings. Coord. Chem. Rev. 2018, 359, 57-79. https://doi.org/10.1016/j.ccr.2018.01.011.

(7) Gong, L.; Lin, Z.; Harms, K.; Meggers, E. Isomerization-Induced Asymmetric Coordination Chemistry : From Auxiliary Control to Asymmetric Catalysis**. Angew. Chemie - Int. Ed. 2010, No. 49, 7955-7957. https://doi.org/10.1002/anie.201003139.

(8) Ruffoni, A.; Juliá, F.; Svejstrup, T. D.; McMillan, A. J.; Douglas, J. J.; Leonori, D. 
Practical and Regioselective Amination of Arenes Using Alkyl Amines. Nat. Chem. 2019, 11, 426-433. https://doi.org/10.1038/s41557-019-0254-5.

(9) Barkay, T.; Miller, S. M.; Summers, A. O. Bacterial Mercury Resistance from Atoms to Ecosystems. FEMS Microbiol. Rev. 2003, 27, 355-384. https://doi.org/10.1016/S0168-6445(03)00046-9.

(10) Edwards, A. M.; Bueno, C.; Saldaño, A.; Silva, E.; Kassab, K.; Polo, L.; Jori, G. Photochemical and Pharmacokinetic Properties of Selected Flavins. J. Photochem. Photobiol. B Biol. 1999, 48, 36-41. https://doi.org/10.1016/S1011-1344(99)000068.

(11) Shu, X.; Lev-Ram, V.; Deerinck, T. J.; Qi, Y.; Ramko, E. B.; Davidson, M. W.; Jin, Y.; Ellisman, M. H.; Tsien, R. Y. A Genetically Encoded Tag for Correlated Light and Electron Microscopy of Intact Cells, Tissues, and Organisms. PLOS Biol. 2011, 9 , e1001041.

(12) Agut, M.; Ruiz-González, R.; Cortajarena, A. L.; Flors, C.; Mejias, S. H.; Nonell, S. Singlet Oxygen Generation by the Genetically Encoded Tag MiniSOG. J. Am. Chem. Soc. 2013, 135, 9564-9567. https://doi.org/10.1021/ja4020524.

(13) Rodríguez-Pulido, A.; Cortajarena, A. L.; Torra, J.; Ruiz-González, R.; Nonell, S.; Flors, C. Assessing the Potential of Photosensitizing Flavoproteins as Tags for Correlative Microscopy. Chem. Commun. 2016, 52, 8405-8408. https://doi.org/10.1039/c6cc03119f.

(14) Proshkina, G. M.; Shramova, E. I.; Shilova, O. N.; Ryabova, A. V.; Deyev, S. M. Phototoxicity of Flavoprotein MiniSOG Induced by Bioluminescence Resonance Energy Transfer in Genetically Encoded System NanoLuc-MiniSOG Is Comparable with Its LED-Excited Phototoxicity. J. Photochem. Photobiol. B Biol. 2018, 188, 107115. https://doi.org/10.1016/j.jphotobiol.2018.09.006.

(15) Souslova, E. A.; Mironova, K. E.; Deyev, S. M. Applications of Genetically Encoded Photosensitizer MiniSOG: From Correlative Light Electron Microscopy to Immunophotosensitizing. J. Biophotonics 2017, 10, 338-352. https://doi.org/10.1002/jbio.201600120.

(16) Varbanov, H. P.; Jakupec, M. A.; Roller, A.; Jensen, F.; Galanski, M.; Keppler, B. K. Theoretical Investigations and Density Functional Theory Based Quantitative Structure-Activity Relationships Model for Novel Cytotoxic Platinum(IV) Complexes. J. Med. Chem. 2013, 56, 330-344. https://doi.org/10.1021/jm3016427.

(17) Englinger, B.; Pirker, C.; Heffeter, P.; Terenzi, A.; Kowol, C. R.; Keppler, B. K.; 
Berger, W. Metal Drugs and the Anticancer Immune Response. Chem. Rev. 2019, 119, 1519-1624. https://doi.org/10.1021/acs.chemrev.8b00396.

(18) Weber, S.; Walker, J. M. Flavins and Flavoproteins IN Series Editor.

(19) Chaiyen, P.; Fraaije, M. W.; Mattevi, A. The Enigmatic Reaction of Flavins with Oxygen. Trends Biochem. Sci. 2012, 37, 373-380. https://doi.org/10.1016/j.tibs.2012.06.005.

(20) Ghisla, S.; Massey, V.; Lhoste, J.-M.; Mayhew, S. G. Fluorescence and Optical Characteristics of Reduced Flavines and Flavoproteins. Biochemistry 1974, 13, 589-597. https://doi.org/10.1021/bi00700a029.

(21) Gargiulo, S.; Arends, I. W. C. E.; Hollmann, F. A Photoenzymatic System for Alcohol Oxidation. ChemCatChem 2011, 3, 338-342. https://doi.org/10.1002/cctc.201000317.

(22) Rauch, M.; Schmidt, S.; Arends, I. W. C. E.; Oppelt, K.; Kara, S.; Hollmann, F. Photobiocatalytic Alcohol Oxidation Using LED Light Sources. Green Chem. 2017, 19, 376-379. https://doi.org/10.1039/c6gc02008a.

(23) Kao, Y.-T.; Saxena, C.; He, T.-F.; Guo, L.; Wang, L.; Sancar, A.; Zhong, D. Ultrafast Dynamics of Flavins in Five Redox States. J. Am. Chem. Soc. 2008, 130, 1313213139. https://doi.org/10.1021/ja8045469.

(24) Feldmeier, C.; Bartling, H.; Magerl, K.; Gschwind, R. M. LED-Illuminated NMR Studies of Flavin-Catalyzed Photooxidations Reveal Solvent Control of the ElectronTransfer Mechanism. Angew. Chemie Int. Ed. 2015, 54, 1347-1351. https://doi.org/10.1002/anie.201409146.

(25) Bartling, H. Dissertation: NMR Spectroscopic Investigations on Photocatalytic Reactions and Photochromic Materials., Universität Regensburg, 2016.

(26) Cardoso, D. R.; Franco, D. W.; Olsen, K.; Andersen, M. L.; Skibsted, L. H. Reactivity of Bovine Whey Proteins, Peptides, and Amino Acids toward Triplet Riboflavin as Studied by Laser Flash Photolysis. J. Agric. Food Chem. 2004, 52, 6602-6606. https://doi.org/10.1021/jf0401165.

(27) Dabbish, E.; Ponte, F.; Russo, N.; Sicilia, E. Antitumor Platinium(IV) Prodrugs: A Systematic Computational Exploration of Their Reduction Mechanism by I-Ascorbic Acid. Inorg. Chem. 2019, 58, 3851-3860. https://doi.org/10.1021/acs.inorgchem.8b03486.

(28) Torra, J.; Lafaye, C.; Signor, L.; Aumonier, S.; Flors, C.; Shu, X.; Nonell, S.; Gotthard, G.; Royant, A. Tailing MiniSOG: Structural Bases of the Complex 
Photophysics of a Flavin-Binding Singlet Oxygen Photosensitizing Protein. Sci. Rep. 2019, 9, 2428. https://doi.org/10.1038/s41598-019-38955-3.

(29) Westberg, M.; Holmegaard, L.; Pimenta, F. M.; Etzerodt, M.; Ogilby, P. R. Rational Design of an Efficient, Genetically Encodable, Protein-Encased Singlet Oxygen Photosensitizer. J. Am. Chem. Soc. 2015, 137, 1632-1642. https://doi.org/10.1021/ja511940j.

(30) Pimenta, F. M.; Jensen, R. L.; Breitenbach, T.; Etzerodt, M.; Ogilby, P. R. OxygenDependent Photochemistry and Photophysics of "MiniSOG," a Protein-Encased Flavin. Photochem. Photobiol. 2013, 89, 1116-1126. https://doi.org/10.1111/php.12111.

(31) Silva, A. V.; López-Sánchez, A.; Junqueira, H. C.; Rivas, L.; Baptista, M. S.; Orellana, G. Riboflavin Derivatives for Enhanced Photodynamic Activity against Leishmania Parasites. Tetrahedron 2015, 71, 457-462. https://doi.org/10.1016/j.tet.2014.11.072.

(32) Varbanov, H. P.; Valiahdi, S. M.; Kowol, C. R.; Jakupec, M. A.; Galanski, M.; Keppler, B. K. Novel Tetracarboxylatoplatinum(IV) Complexes as Carboplatin Prodrugs. Dalton. Trans. 2012, 41, 14404-14415. https://doi.org/10.1039/C2DT31366A.

(33) Gramatica, P.; Papa, E.; Luini, M.; Monti, E.; Gariboldi, M. B.; Ravera, M.; Gabano, E.; Gaviglio, L.; Osella, D. Antiproliferative Pt(IV) Complexes: Synthesis, Biological Activity, and Quantitative Structure-Activity Relationship Modeling. JBIC J. Biol. Inorg. Chem. 2010, 15, 1157-1169. https://doi.org/10.1007/s00775-010-0676-4.

(34) Tetko, I. V; Varbanov, H. P.; Galanski, M.; Talmaciu, M.; Platts, J. A.; Ravera, M.; Gabano, E. Prediction of LogP for Pt(II) and Pt(IV) Complexes: Comparison of Statistical and Quantum-Chemistry Based Approaches. J. Inorg. Biochem. 2016, 156, 1-13. https://doi.org/https://doi.org/10.1016/j.jinorgbio.2015.12.006.

(35) Jhulki, I.; Chanani, P. K.; Abdelwahed, S. H.; Begley, T. P. A Remarkable Oxidative Cascade That Replaces the Riboflavin C8 Methyl with an Amino Group during Roseoflavin Biosynthesis. J. Am. Chem. Soc. 2016, 138, 8324-8327. https://doi.org/10.1021/jacs.6b02469.

(36) Rabello, B. R.; Gerola, A. P.; Pellosi, D. S.; Tessaro, A. L.; Aparício, J. L.; Caetano, W.; Hioka, N. Singlet Oxygen Dosimetry Using Uric Acid as a Chemical Probe: Systematic Evaluation. J. Photochem. Photobiol. A Chem. 2012, 238, 53-62. https://doi.org/10.1016/j.jphotochem.2012.04.012. 
(37) Gomes, A.; Fernandes, E.; Lima, J. L. F. C. Fluorescence Probes Used for Detection of Reactive Oxygen Species. J. Biochem. Biophys. Methods 2005, 65, 45-80. https://doi.org/10.1016/j.jbbm.2005.10.003.

(38) Frisch, M. J.; Trucks, G. W.; Schlegel, H. B.; Scuseria, G. E.; Robb, M. A.; Cheeseman, J. R.; Scalmani, G.; Barone, V.; Petersson, G. A.; Nakatsuji, H.; Li, X.; Caricato, M.; Marenich, A. V; Bloino, J.; Janesko, B. G.; Gomperts, R.; Mennucci, B.; Hratchian, H. P.; Ortiz, J. V; Izmaylov, A. F.; Sonnenberg, J. L.; Williams-Young, D.; Ding, F.; Lipparini, F.; Egidi, F.; Goings, J.; Peng, B.; Petrone, A.; Henderson, T.; Ranasinghe, D.; Zakrzewski, V. G.; Gao, J.; Rega, N.; Zheng, G.; Liang, W.; Hada, M.; Ehara, M.; Toyota, K.; Fukuda, R.; Hasegawa, J.; Ishida, M.; Nakajima, T.; Honda, Y.; Kitao, O.; Nakai, H.; Vreven, T.; Throssell, K.; Montgomery Jr., J. A.; Peralta, J. E.; Ogliaro, F.; Bearpark, M. J.; Heyd, J. J.; Brothers, E. N.; Kudin, K. N.; Staroverov, V. N.; Keith, T. A.; Kobayashi, R.; Normand, J.; Raghavachari, K.; Rendell, A. P.; Burant, J. C.; Iyengar, S. S.; Tomasi, J.; Cossi, M.; Millam, J. M.; Klene, M.; Adamo, C.; Cammi, R.; Ochterski, J. W.; Martin, R. L.; Morokuma, K.; Farkas, O.; Foresman, J. B.; Fox, D. J. Gaussian 16, Revision B.01. 2016.

(39) Adamo, C.; Barone, V. Toward Reliable Density Functional Methods without Adjustable Parameters: The PBE0 Model. J. Chem. Phys. 1999, 110, 6158-6170. https://doi.org/10.1063/1.478522.

(40) Weigend, F.; Ahlrichs, R. Balanced Basis Sets of Split Valence, Triple Zeta Valence and Quadruple Zeta Valence Quality for $\mathrm{H}$ to Rn: Design and Assessment of Accuracy. Phys. Chem. Chem. Phys. 2005, 7, 3297-3305. https://doi.org/10.1039/B508541A.

(41) Grimme, S.; Ehrlich, S.; Goerigk, L. Effect of the Damping Function in Dispersion Corrected Density Functional Theory. J. Comput. Chem. 2011, 32, 1456-1465. https://doi.org/10.1002/jcc.21759.

(42) Chai, J.-D.; Head-Gordon, M. Long-Range Corrected Hybrid Density Functionals with Damped Atom-Atom Dispersion Corrections. Phys. Chem. Chem. Phys. 2008, 10, 6615-6620. https://doi.org/10.1039/B810189B.

(43) Zhao, Y.; Truhlar, D. G. The M06 Suite of Density Functionals for Main Group Thermochemistry, Thermochemical Kinetics, Noncovalent Interactions, Excited States, and Transition Elements: Two New Functionals and Systematic Testing of Four M06-Class Functionals and 12 Other Function. Theor. Chem. Acc. 2008, 120, 215-241. https://doi.org/10.1007/s00214-007-0310-x. 
(44) Reed, A. E.; Curtiss, L. A.; Weinhold, F. Intermolecular Interactions from a Natural Bond Orbital, Donor-Acceptor Viewpoint. Chem. Rev. 1988, 88, 899-926. https://doi.org/10.1021/cr00088a005.

(45) Chirlian, L. E.; Francl, M. M. Atomic Charges Derived from Electrostatic Potentials: A Detailed Study. J. Comput. Chem. 1987, 8, 894-905. https://doi.org/10.1002/jcc.540080616. 